\title{
Highly Efficient Adsorption and Removal of Amoxicillin from Aqueous Solution by Magnetic Graphene Oxide Nanocomposite
}

\author{
Ferdos Kord Mostafapour ${ }^{1}$, Maryam Bazi ${ }^{2}$, Shaziya Haseeb Siddiqui ${ }^{3}$, Hossein Bagheri ${ }^{4}$, Davoud Balarak ${ }^{1, *}$ \\ 'Department of Environmental Health Engineering, Health Promotion Research Center, Zahedan University of Medical Sciences, Zahedan, IRAN. \\ ${ }^{2}$ Student Research Committee, Zahedan University of Medical Sciences, Zahedan, IRAN. \\ 3Department of Chemistry, Sam Higginbottom University of Agriculture Technology and Sciences (SHUATS), Allahabad, Uttar Pradesh, INDIA. \\ ${ }^{4}$ Department of Medical Language, Zahedan University of Medical Sciences, Zahedan, IRAN.
}

\begin{abstract}
Background: Antibiotics have lasting effects on the environment. Among the properties of these substances are non-biodegradable, carcinogenic, high toxicity, and an increase in antibiotic-resistant bacteria. Therefore, they should be removed from aqueous solutions and the point of this think was to adsorb amoxicillin (AMO) by magnetic graphene oxide nanocomposite (MGO). Methods: The adsorption behavior of AMO was studied in a series of batch experiments as a function of $\mathrm{pH}$ (3-11), contact time (0-120 min), and AMO concentration (10-100 mg/L) different MGO dosages (0.1-1 g/L). The structures of MGO were confirmed by scanning electron microscope (SEM), and the X-ray diffraction (XRD) Results: The results revealed in optimized conditions $(\mathrm{pH}=3$, contact time $=75 \mathrm{~min}, \mathrm{AMO}$ concentration $=10 \mathrm{mg} / \mathrm{L}$ and adsorbent dose $=0.75 \mathrm{~g} / \mathrm{L}$ ) maximum adsorption capacity and removal efficiency of AMO were $98.41 \mathrm{mg} / \mathrm{g}$, respectively. The thermodynamical parameters showed that
\end{abstract}

the sorption method was endothermal and spontaneous. Conclusion: MGO nanoparticles have extended capabilities such as easy and rapid separation from solution and high potential in removing AMO, so, it can be introduced as an appropriate adsorbent for removal of this antibiotics from water and wastewater.

Key words: Amoxicillin, Magnetic graphene oxide, Thermodynamics, Adsorption, Nanocomposite.

\section{Correspondence}

\section{Dr. Davoud Balarak}

Department of Environmental Health, Health Promotion Research Center, Zahedan University of Medical Sciences, Zahedan, IRAN.

Email id: dbalarak2@gmail.com

DOI: 10.5530/ijpi.2021.4.69

\section{INTRODUCTION}

Drugs and personal care products are widely used in various fields such as medicine, agriculture, aquaculture and animal husbandry in people's daily lives. ${ }^{1,2}$ The presence of drugs in wastewater causes many environmental problems. ${ }^{3,4}$ Global drug production has been on the rise since 2000, with penicillin production reaching 28,000 tons per year in 2003, equivalent to 60 percent of global antibiotic use per year. ${ }^{5,6}$ More than 50 antibiotics are produced worldwide, including amoxicillin, penicillin and ciprofloxacin, more than any other antibiotic. ${ }^{7,8}$ Amoxicillin is beta-lactam groups of drugs, which is prescribed for the treatment of infections of the body and as an antiviral drug for humans. ${ }^{9}$ Although its concentration in the environment is very low, but it can easily affect the quality of water and ecosystem and pose a serious threat to the environment. ${ }^{10}$ The presence of beta-lactam rings in the chemical structure of amoxicillin, in addition to preventing the growth of bacteria, leads to their elimination on the cell-wall. ${ }^{11,12}$ About 30 to $90 \%$ of drug compounds are not metabolized in humans and animals and enter the environment through urine or feces as an active compound, which will have serious and dangerous consequences. ${ }^{13,14}$ Municipal wastewater treatment plants do not have the capacity to remove active pharmaceutical compounds from the environment. ${ }^{15,16}$ Therefore, many technologies have been used to remove drug compounds from effluents, which can be advanced oxidation processes, photocatalytic degradation, chemical degradation, ion exchange, bioreactor, nanofiltration, membrane processes, adsorption..$^{17,18}$

In this study, the adsorption method was used to remove the antibiotic. Process adsorption It is used to isolate many organic and inorganic pollutants. ${ }^{19}$ This process due to low cost, High flexibility, easy design and efficiency, and high ability to remove toxic and hazardous substances as a suitable method of absorption antibiotic pollutants are used..$^{20,21}$

Adsorption of antibiotic compounds from aqueous solution before they enter the environment and cause pollution carbon nanostructures have been studied. ${ }^{22}$ The use of nanostructures increases the surface to volume ratio and the absorption process is more desirable. ${ }^{23}$ Avoid the problem of separating the adsorbent from the solution in these methods it is impossible. ${ }^{24}$ As the nanosorbent disperses in solution, centrifugation and robust separation systems are required. ${ }^{25}$ Therefore, in order to use the absorbent and easy separation, the nanostructured surface is modified. Therefore, to achieve this goal of graphene and magnetic graphene nanosorbents have been used. The bonding of magnetic iron oxide nanoparticles to graphene combines the high adsorption capacity of graphene and the ease of separation of magnetic nanoparticles. ${ }^{26}$

Therefore, we investigated the uptake of adsorb amoxicillin (AMO) by magnetic graphene oxide nanocomposite (MGO) nanoparticles. In this work, the effect of different parameters such as contact time and AMO concentration and adsorbent dose and $\mathrm{pH}$ was investigated.

\section{MATERIALS AND METHODS}

This is an applied experimental study that was performed on samples of laboratory synthetic wastewater to determine the effect of graphene on the absorption of AMO. Materials used in this study are high purity AMO powder, 99\% graphite and $\mathrm{HCl}$ and $\mathrm{NaOH} 0.1 \mathrm{~N}, \mathrm{H}_{2} \mathrm{SO}_{4}$ was $1 \mathrm{~N}$, which was prepared from Merck company. All samples used in this study

This is an open access article distributed under the terms of the Creative Commons Attribution-NonCommercial-ShareAlike 4.0 License, which allows others to remix, tweak, and build upon the work non-commercially, as long as the author is credited and the new creations are licensed under the identical terms. 
were prepared in a volume of $100 \mathrm{ml}$ and was prepared from a stock sample with a concentration of $1 \mathrm{~g}$ per liter of distilled water.

\section{Synthesis of magnetic graphene oxide}

Graphene oxide (GO) was synthesized from natural graphite by the Hummers method. $69 \mathrm{ml}$ of sulfuric acid $(1 \mathrm{M})$ to a mixture of $3 \mathrm{~g}$ of graphite and $2.5 \mathrm{~g}$ of sodium nitrate were added. The mixture was cooled to $5^{\circ} \mathrm{C}$ and stirred for $2 \mathrm{hr}$. Then $9 \mathrm{~g}$ of $\mathrm{KMnO}_{4}$ was added at temperature below $10^{\circ} \mathrm{C}$. The solution was stirred in water at $35^{\circ} \mathrm{C}$ for half an hour. Then, with the addition of $238 \mathrm{ml}$ of distilled water to the solution at $80^{\circ} \mathrm{C}$, stirring was continued for half an hour. Then $410 \mathrm{ml}$ of distilled water was slowly added to the mixture. To obtain a colorless solution of manganese sulfate, $30 \mathrm{ml}$ of $30 \% \mathrm{H}_{2} \mathrm{O}_{2}$ was slowly added to the mixture. The solution was then centrifuged and washed with $5 \% \mathrm{HCl}$ and water. After filtration, it was dried at $65^{\circ} \mathrm{C}$ to obtain graphite oxide. Then prepare $0.5 \mathrm{~g}$ solution per liter of graphite oxide and ultrasonic for one hour to obtain GO solution.

For magnetic graphene synthesized first $0.5 \mathrm{~g}$ of GO was dispersed in $100 \mathrm{ml}$ of water and $2.7 \mathrm{~g}$ of ammonium ferrous sulfate and $1.52 \mathrm{~g}$ of ammonium ferric sulfate were added to the mixture and ultrasonic under nitrogen at $50^{\circ} \mathrm{C}$ for $20 \mathrm{~min}$ and $20 \mathrm{ml}$ of $8 \mathrm{M}$ aqueous ammonia solution was slowly added to the solution. The mixture was then stirred for $60 \mathrm{~min}$ at $50^{\circ} \mathrm{C}$. The black precipitate of magnetic nanoparticles was collected by magnet and washed with distilled water. The nanocomposite was then dried for two hours at $80^{\circ} \mathrm{C}$.

In this study, time, $\mathrm{pH}, \mathrm{AMO}$ concentration, adsorbent dose was examined to identify the most optimal values of these variables. All adsorption experiments were performed with two replications and their mean values were used as final results in the calculations. Finally, isotherm and adsorption kinetics experiments were performed under optimal conditions.

\section{RESULTS}

Figure 1 in order of images (SEM) for scanning electron microscopy analysis for MGO Shows before and after the adsorption process. $\mathrm{He}$ analysis is performed to investigate the morphology and surface properties of graphene. In the picture, it can be seen that graphene oxide has a sheet shape and has a suitable porosity, which will increase the level of contact of the contaminant with the adsorbent and consequently increase the adsorption efficiency.

The X-ray purification pattern (XRD) for the magnetic graphene oxide studied in the range of $10-70$ using $\mathrm{Cu}$ ka radiation at $25^{\circ} \mathrm{C}$ is shown in Figure 2. According to this analysis, the peaks created at angles of 11.7 and 25.2 degrees indicate the presence of graphene oxide. The presence of peaks at angles of 18.3 and 30.2, 35.6, 43.2, 53.8, 57.2 degrees according to JCPDS Card\#19-629 protocol indicates the presence of iron oxide in the synthesized adsorbent structure. It can be reported that XRD oxide has been successfully synthesized based on the results of magnetic graphene analysis.

To determine the ideal dose of the adsorbent, amounts of MGO were varied from 0.1 to $1 \mathrm{~g} / \mathrm{L}$. Figure 3 shows the removal percentages (\%) and different doses of MGO. It was observed that the amount of AMO adsorbed onto the unit weight of the sorbent increased from 0.1 to $0.75 \mathrm{~g}$. The maximum removal was observed at $0.75 \mathrm{~g}$ with percentages of 98.4.

To determine the ideal absorbent dose, the amount of MGO ranged from 0.1 to $1 \mathrm{~g} / \mathrm{L}$. Figure 3 shows removal (\%) and different doses of MGO. It was observed that the amount of AMO adsorbed on the weight of the adsorbent unit increased from 0.1 to $0.75 \mathrm{~g}$. A maximum removal of 0.75 g was observed with $98.4 \%$.
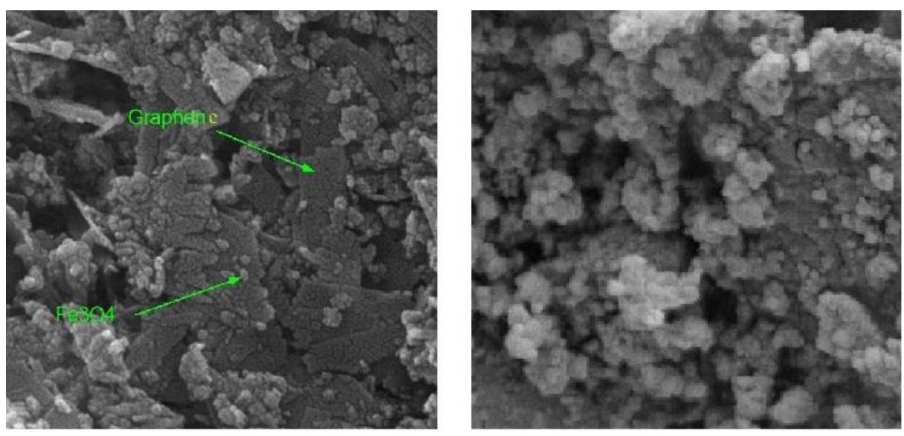

Figure 1: SEM pattern of MGO nanocomposite.

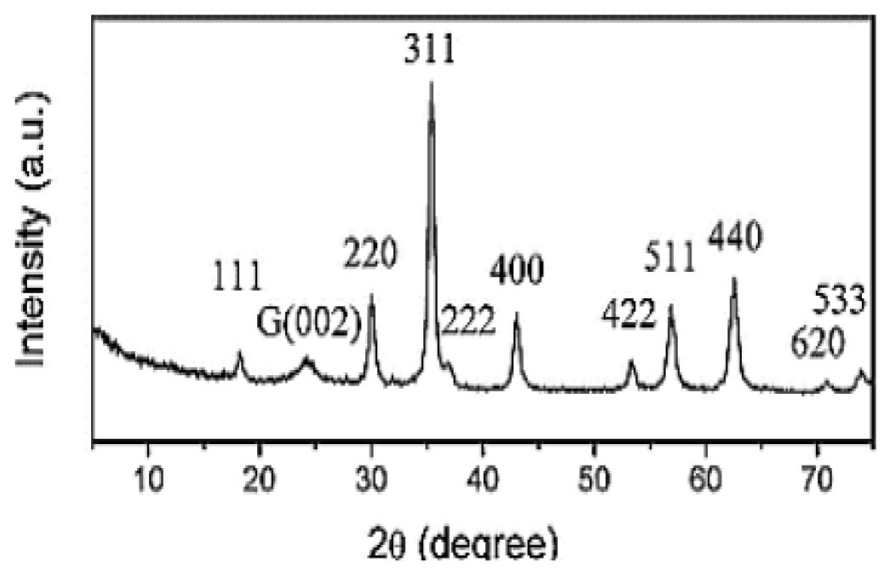

Figure 2: XRD pattern of MGO nanocomposite.

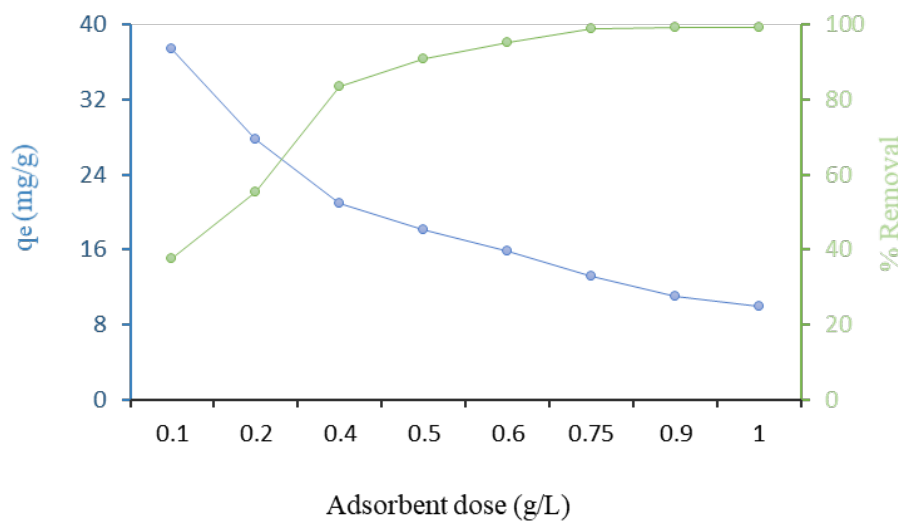

Figure 3: Effect of adsorbent dose on removal percentage of AMO $\left(C_{0}=10 \mathrm{mg} / \mathrm{L}, \mathrm{pH}=3\right.$, time $=75 \mathrm{~min}$ and $\left.\mathrm{Tem}: 25^{\circ} \mathrm{C}\right)$.

The efficiency of MGO composites on AMO uptake at various $\mathrm{pH}$ levels is presented in Figure 4. It can be seen that AMO elimination efficiencies decreased with an increase in $\mathrm{pH}$ scope of 5-11, and that there was no increase in adsorption beyond this $\mathrm{pH}$ range. The maximum removal was achieved at $\mathrm{pH}$ levels of 3-5 with removal percentages of 98.4.

The influence of the various preliminary pollutant concentrations on AMO uptake by MGO nanoparticles was examined at concentrations $(10-100 \mathrm{mg} / \mathrm{L})$. From the achieved results presented in Figure 5, it can be observed that the adsorption of AMO is dependent on the AMO concentration, and decreasing at a higher initial concentration. The 


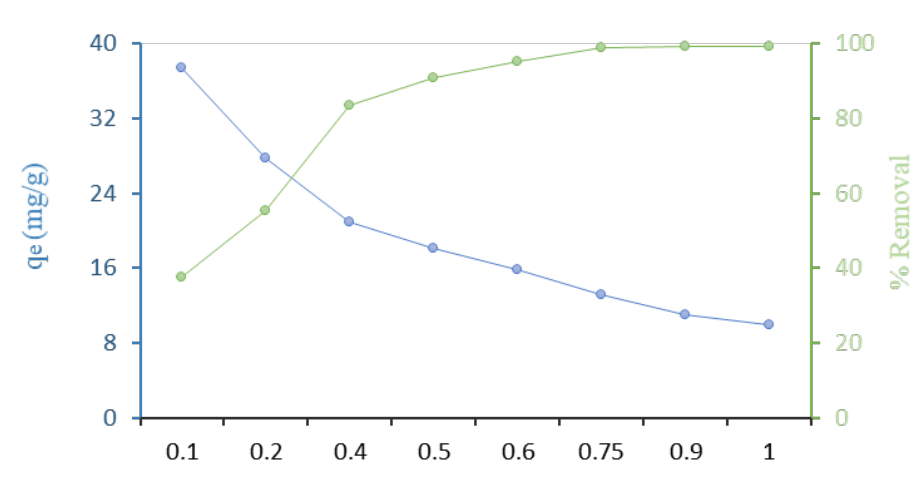

Adsorbent dose $(\mathrm{g} / \mathrm{L})$

Figure 4: Effect of $\mathrm{pH}$ on removal percentage of $\mathrm{AMO}$ (time $=75 \mathrm{~min}$, $\mathrm{C}_{0}=10 \mathrm{mg} / \mathrm{L}$, tem: $25^{\circ} \mathrm{C}$ and $\mathrm{MGO}$ dose $=0.75 \mathrm{~g} / \mathrm{L}$ ).

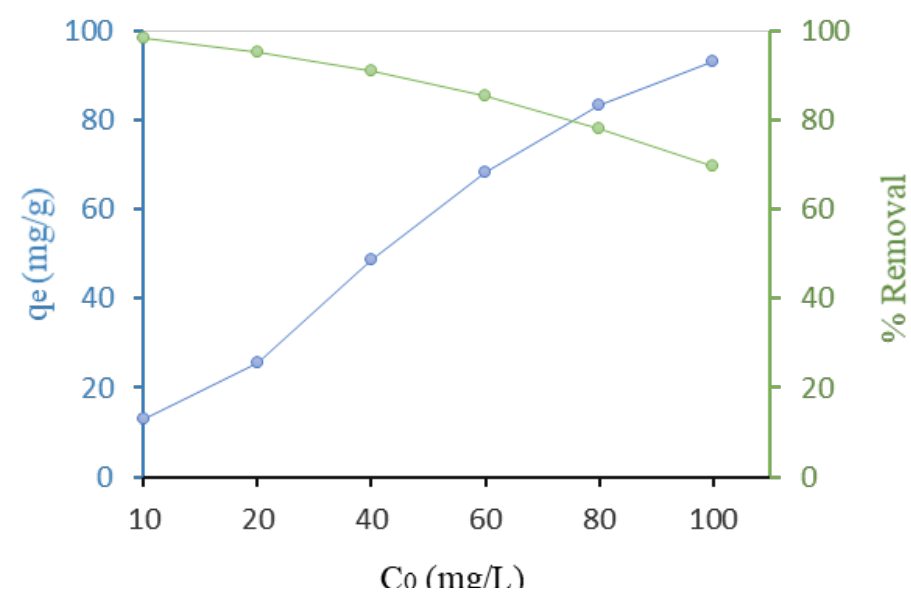

Figure 5: Effect of initial $A M O$ concentration on removal percentage of AMO (time $=75 \mathrm{~min}, \mathrm{pH}=3$, tem: $25^{\circ} \mathrm{C}$ and $\mathrm{MGO}$ dose $=0.75 \mathrm{~g} / \mathrm{L}$ ).

results showed that the amount of AMO adsorbed per unit mass of adsorbent increased from 13.95 to $92.39 \mathrm{mg} / \mathrm{g}$.

Figure 6 shows the influence of adsorption time by utilizing MGO containing $0.75 \mathrm{~g}$ of adsorbent. The results show adsorption of AMO increased sharply in the initial $30 \mathrm{~min}$ and then increased slowly until it reached removal levels in a period of $75 \mathrm{~min}$. Adsorption time increased from 59.54 to $84.30 \%$ and augmented from 75.4 to $98.4 \%$ with an increase in contact time from 30 to $75 \mathrm{~min}$.

\section{DISCUSSION}

The uptake of amoxicillin was evaluated between 0 and $120 \mathrm{~min}$ and the effect of time on changes in adsorption, it should be observed that the removal process had an acceptable speed and the maximum amount of adsorption was achieved in $75 \mathrm{~min}$. However, at times higher than $75 \mathrm{~min}$, the absorption is steady and balanced and has subtle changes. Initially, the process has a high rate of adsorption due to the presence of voids that have the ability to trap contaminant molecules, ${ }^{27}$ while with increasing time due to saturation of existing voids, the adsorption efficiency decreases. ${ }^{28,29}$

Darweesh et al. Obtained a time of $60 \mathrm{~min}$ as the optimal time for norfloxacin removal by the granular activated carbon. The cause of fluctuations in adsorption time in studies can be due to differences in

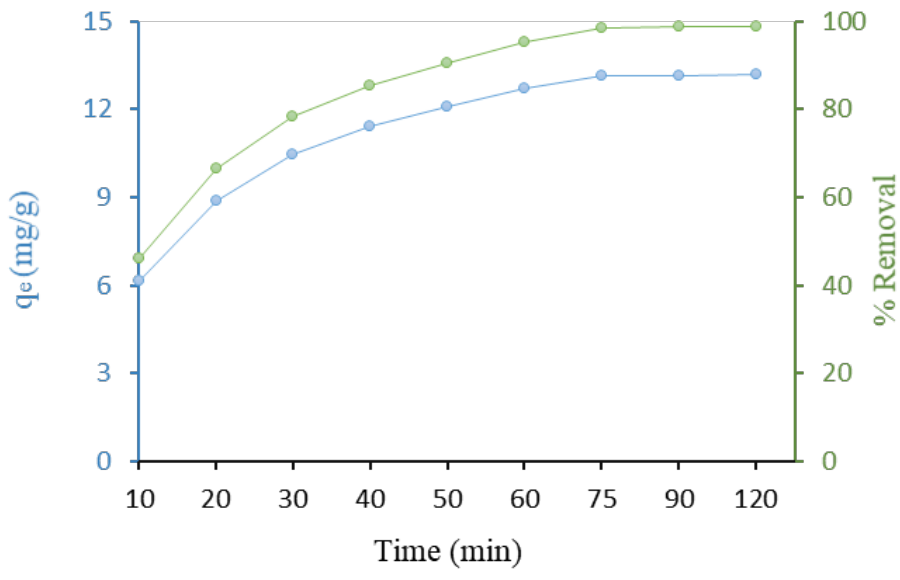

Figure 6: Effect of contact time on removal percentage of AMO $\left(\mathrm{C}_{0}=10 \mathrm{mg} / \mathrm{L}, \mathrm{pH}=3, \mathrm{Tem}: 25^{\circ} \mathrm{C}\right.$ and $\mathrm{MGO}$ dose $\left.=0.75 \mathrm{~g} / \mathrm{L}\right)$.

the type of pollutant, adsorbent synthesis method and also differences in pollutant concentrations used to determine the equilibrium time. ${ }^{30}$

Adsorption increases with increasing absorbent dose and decreasing contaminant concentration. The optimal adsorbent dose in the present study was $0.75 \mathrm{~g} / \mathrm{L}$. It is necessary to explain that in higher concentrations due to a slight increase in removal efficiency and due to economic issues, ${ }^{31-33}$ the best adsorbent of $0.75 \mathrm{~g}$ was selected and introduced. This result can be explained by the fact that by increasing the concentration of adsorbent in the sample, the available levels and locations of the adsorbent for the contaminant increase and increase the adsorption efficiency of the contaminant, while at lower doses of adsorbent, the adsorption sites are rapidly saturated by the contaminant. ${ }^{34,35}$

The highest rate of deletion occurs at a $\mathrm{pH}$ of 3 with a removal percentage of 98.41 achieved. This is because the adsorption capacity is highly $\mathrm{pH}$ dependent and the adsorption mechanism depends on the surface charge of the adsorbent and the AMO ions in solution. ${ }^{36,37}$

It can be noted that at low $\mathrm{pH}$ values, the binding capacity of AMO is increased due to the anionic properties of the antibiotic. ${ }^{38}$ In addition, the MGO levels represent an anionic group $\left(\mathrm{COO}^{-}\right)$and subsequently improve their particle exchange properties for specific treatments of oppositely charged species (AMO) of aqueous mixtures through the electrostatic power of their interaction. ${ }^{39}$

Ji et al. ${ }^{38}$ examined the sorption of TC on MWCNT and graphite, and the elimination of this tetracycline was achieved at $\mathrm{pH}$ 2. Moreover, Balarak et al..$^{39}$ determined that at acidic $\mathrm{pH}$ situations, a positively charged external sites on Lemna minor prefer the sorption of CIP anions owing to the electrostatic enchantment, and the $\mathrm{pH}$ of the ciprofloxacin solution.

The data showed that the increase at the initial AMO concentration improves the quantity of AMO adsorbed onto the MGO. The increase in the adsorption capacity is possibly owing to greater interaction among the AMO and MGO in addition to an increase in the number of AMO particle collisions that increase the driving force of the concentration gradient with the increase in the initial concentration to overcome all resistances of the AMO mass transfer among the solid phases and liquid..$^{40,41}$ Moreover, the higher amount of AMO adsorption at higher concentrations is probably because of increased diffusion and reduced resistance to AMO uptake. ${ }^{42}$

Results demonstrates that the adsorption process of AMO by MGO decreased with increasing temperature and indicating that the processes are exothermic. Because the adsorptive powers among AMO and active 
sites on the MGO became weak with the increase in temperature, AMO removal efficiency decreased. ${ }^{43}$

Conventional treatment technologies for the elimination of AMO from aqueous effluents are not economical, expensive, and difficult to operate and produce huge amounts of toxic chemical sludge. ${ }^{27}$ However, in this technical application, the low cost of prepared materials, the phenomenon of rapid adsorption happens at the shorter contact time with small quantities of MGO and its regeneration for more cycles with a high yield, which enables a smaller size of the contact apparatus, which in turn directly affects the running cost and the ability of the technique.

\section{CONCLUSION}

This study demonstrated that the MGO in this work is effective adsorbents at complete adsorption of AMO from an aqueous solution. MGO was prepared by the Hummers method, a cheap technique. The batch process conditions have a significant influence on the removal process, where increasing the MGO dose has a directly proportional effect on the AMO adsorption process. In addition, it was shown that the adsorption of AMO is favored at a low AMO concentration and $\mathrm{pH}$. The adsorption of AMO was exothermic, a spontaneous process, and the reaction of adsorption is a physisorption process. Therefore, this research confirms that adsorption of AMO by using MGO led to an efficient improvement in the removal process of AMO from aqueous solution in a short adsorption time.

\section{ACKNOWLEDGEMENT}

The authors are grateful from Student Research Committee, Zahedan University of Medical Sciences, because of supporting of this research.

\section{CONFLICT OF INTEREST}

The authors declare no conflict of interest.

\section{ABBREVIATIONS}

MGO: Magnetic graphene oxide; AMO: Amoxicillin.

\section{REFERENCES}

1. Putra EK, Pranowo R, Sunarso J, Indraswati N, Ismadji S. Performance of activated carbon and bentonite for adsorption of amoxicillin from wastewater: mechanism, isotherms and kinetics. Water Res. 2009;43(9):2419-30. doi: 10.1016/j.watres.2009.02.039, PMID 19327813.

2. Bi PY, Dong HR, Guo QZ. Separation and Purification of penicillin G from fermentation broth by solvent sublation. Sep Purif Technol. 2009;65(2):228-31. doi: 10.1016/j.seppur.2008.10.028.

3. Peterson JW, Petrasky LJ, Seymour MD, Burkhart RS, Schuiling AB Adsorption and breakdown of penicillin antibiotic in the presence of titanium oxide nanoparticles in water. Chemosphere. 2012;87(8):911-17. doi: 10.1016/j. chemosphere.2012.01.044, PMID 22342282.

4. Yaghmaeian K, Moussavi G, Alahabadi A. Removal of amoxicillin from contaminated water using $\mathrm{NH}_{4} \mathrm{Cl}$-activated carbon: continuous flow fixed-bed adsorption and catalytic ozonation regeneration. Chem Eng J. 2014;236:538-44. doi: 10.1016/j.cej.2013.08.118.

5. Aksu Z, Tunç Ö. Application of biosorption for penicillin G removal: comparison with activated carbon. Process Biochem. 2005;40(2):831-47. doi: 10.1016/j. procbio.2004.02.014

6. Bazi M, Balarak D, Dokht Khatibi A, Haseeb Siddiqui S, Kord Mostafapour F Investigation of Isotherm, Kinetics and Thermodynamics of Ciprofloxacin Adsorption by Molecularly Imprinted Polymer from Aqueous Solutions. Int J Pharm Investig. 2021;11(3): 269-273

7. Bui TX, Choi H. Adsorptive removal of selected pharmaceuticals by mesoporous silica SBA-15. J Hazard Mater. 2009;168(2-3):602-8. doi: 10.1016/j. jhazmat.2009.02.072, PMID 19327889.

8. Choi KJ, Kim SG, Kim SH. Removal of antibiotics by coagulation and granular activated carbon filtration. J Hazard Mater. 2008;151(1):38-43. doi: 10.1016/j. jhazmat.2007.05.059, PMID 17628341.

9. Ding R, Zhang P, Seredych M, Bandosz TJ. Removal of antibiotics from water using sewage sludge- and waste oil sludge-derived adsorbents. Water Res. 2012;46(13):4081-90. doi: 10.1016/j.watres.2012.05.013, PMID 22673337.
10. Crisafully R, Milhome MAL, Cavalcante RM, Silveira ER, De Keukeleire D, Nascimento RF. Removal of some polycyclic aromatic hydrocarbons from petrochemical wastewater using low-cost adsorbents of natural origin Bioresour Technol. 2008;99(10):4515-19. doi: 10.1016/j.biortech.2007.08.041, PMID 17964147.

11. Ali I. New generation adsorbents for water treatment. Chem Rev 2012;112(10):5073-91. doi: 10.1021/cr300133d, PMID 22731247.

12. Gupta VK, Ali I, Suhas D, Mohan D. Equilibrium uptake and sorption dynamics for the removal of a basic dye (basic red) using low-cost adsorbents. J Colloid Interface Sci. 2003;265(2):257-64. doi: 10.1016/s0021-9797(03)00467-3, PMID 12962659.

13. Zhang L, Song X, Liu X, Yang L, Pan F, Lv J. Studies on the removal of tetracycline by multi-walled carbon nanotubes. Chem Eng J. 2011;178:26-33. doi: 10.1016/j. cej.2011.09.127.

14. Mohammadi AS, Sardar M. The removal of penicillin $G$ from aqueous solutions using chestnut shell modified with $\mathrm{H}_{2} \mathrm{SO}_{4}$ : isotherm and kinetic study. J Health Environ. 2012;6(1):497-508.

15. Rahardjo AK, Susanto MJ, Kurniawan A, Indraswati N, Ismadji S. Modified Ponorogo bentonite for the removal of ampicillin from wastewater. J Hazard Mater. 2011;190(1-3):1001-8. doi: 10.1016/j.jhazmat.2011.04.052, PMID 21550716.

16. Zhang $\mathrm{CL}$, Qiao GL, Zhao F, Wang Y. Thermodynamic and kinetic parameters of ciprofloxacin adsorption onto modified coal fly ash from aqueous solution. J Mol Liq. 2011;163(1):53-6. doi: 10.1016/j.molliq.2011.07.005.

17. Rivera-Utrilla J, Prados-Joya G, Sánchez-Polo M, Ferro-García MA, BautistaToledo I. Removal of nitroimidazole antibiotics from aqueous solution by adsorption/bioadsorption on activated carbon. J Hazard Mater. 2009;170(1):298305. doi: 10.1016/j.jhazmat.2009.04.096, PMID 19464791.

18. Gulkowska A, Leung HW, So MK, Taniyasu S, Yamashita N, Yeung LWY Richardson BJ, Lei AP, Giesy JP, Lam PKS. Removal of antibiotics from wastewater by sewage treatment facilities in Hong Kong and Shenzhen, China. Water Res. 2008;42(1-2):395-403. doi: 10.1016/j.watres.2007.07.031.

19. Adriano WS, Veredas V, Santana CC, Gonçalves LRB. Adsorption of amoxicillin on chitosan beads: kinetics, equilibrium and validation of finite bath models. Biochem Eng J. 2005;27(2):132-37. doi: 10.1016/j.bej.2005.08.010.

20. Moein H, Balarak D, Meshkinain A, Chandrika K, Yazdani N. Effects of operational parameters on the removal of tetracycline from aqueous solutions by electrocoagulation. Int J Pharm Investig. 2021;11(1):23-6. doi: 10.5530/ijpi.2021.1.5.

21. Balarak D, Baniasadi M, Bazzi M. Adsorption equilibrium and thermodynamic studies of ciprofloxacin from aqueous solutions by magnetic bentonite nanocomposites. Int J Pharm Investig. 2020;10(3):339-43. doi: 10.5530/ ijpi.2020.3.60

22. Lv JM, Ma YL, Chang $X$, Fan SB. Removal and removing mechanism of tetracycline residue from aqueous solution by using $\mathrm{Cu}-13 \mathrm{X}$. Chem Eng J. 2015;273:247-53. doi: 10.1016/j.cej.2015.03.080.

23. Rostamian R, Behnejad H. A comparative adsorption study of sulfamethoxazole onto graphene and graphene oxide nanosheets through equilibrium, kinetic and thermodynamic modeling. Process Saf Environ Prot. 2016:102:20-9. doi: 10.1016/j.psep.2015.12.011.

24. Chen H, Gao B, Li H. Removal of sulfamethoxazole and ciprofloxacin from aqueous solutions by graphene oxide. J Hazard Mater. 2015;282:201-7. doi 10.1016/j.jhazmat.2014.03.063, PMID 24755346

25. Peng X, Hu F, Dai H, Xiong $Q$, Xu C. Study of the adsorption mechanisms of ciprofloxacin antibiotics onto graphitic ordered mesoporous carbons. J Taiwan Inst Chem Eng. 2016;65:472-81. doi: 10.1016/j.jtice.2016.05.016.

26. Parsa JB, Panah TM, Chianeh FN. Removal of ciprofloxacin from aqueous solution by a continuous flow electro-coagulation process. Korean J Chem Eng 2016:33(3):893-901. doi: 10.1007/s11814-015-0196-6.

27. Ahmadi S, Banach A. Kord Mostafapour F. Study survey of cupric oxide nanoparticles in removal efficiency of ciprofloxacin antibiotic from aqueous solution: adsorption isotherm study. Desalin Water Treat. 2017;89:297-303.

28. Acosta R, Fierro V, Martinez de Yuso AM, Nabarlatz D, Celzard A. Tetracycline adsorption onto activated carbons produced by $\mathrm{KOH}$ activation of tyre pyrolysis char. Chemosphere. 2016;149:168-76. doi: 10.1016/j.chemosphere.2016.01.093, PMID 26855221.

29. Balarak D, Khatibi AD, Chandrika K. Antibiotics removal from aqueous solution and pharmaceutical wastewater by adsorption process: a review. Int J Pharm Investig. 2020;10(2):106-11. doi: 10.5530/ijpi.2020.2.19.

30. Darweesh TM, Ahmed MJ. Adsorption of ciprofloxacin and norfloxacin from aqueous solution onto granular activated carbon in fixed bed column. Ecotoxicol Environ Saf. 2017:138:139-45. doi: 10.1016/j.ecoenv.2016.12.032, PMID 28040619.

31. Mostafapour FK, Haseeb $S$, Balarak D, Moein $H$, Sajadi AA Jalalzaei Z Thermodynamic study of amoxicillin and naphthalene adsorption on activated carbon derived from Salvadora persica. Int J Pharm Investig. 2021;11(1):41-5 doi: 10.5530/ijpi.2021.1.8.

32. Lu W, Liu J, Li J, Wang X, Lv M, Cui R, Chen L. Dual-template molecularly imprinted polymers for dispersive solid-phase extraction of fluoroquinolones in water samples coupled with high performance liquid chromatography. Analyst. 2019;144(4):1292-302. doi: 10.1039/c8an02133c, PMID 30548030. 
33. Pupin RR, Foguel MV, Gonçalves LM, Sotomayor MdPT. Magnetic molecularly imprinted polymers obtained by photopolymerization for selective recognition of penicillin G. J Appl Polym Sci. 2020;137(13):1-10. doi: 10.1002/app.48496.

34. Li M, LiuY, Liu S, Shu D, Zeng G, Hu X, Tan X, Jiang L, Yan Z, CaiX. Cu(II)-influenced adsorption of ciprofloxacin from aqueous solutions by magnetic graphene oxide/nitrilotriacetic acid nanocomposite: competition and enhancement mechanisms. Chem Eng J. 2017;319:219-28. doi: 10.1016/j.cej.2017.03.016.

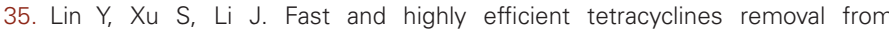
environmental waters by graphene oxide functionalized magnetic particles. Chem Eng J. 2013;225:679-85. doi: 10.1016/j.cej.2013.03.104.

36. Li G, Zhang D, Wang M, Huang J, Huang L. Preparation of activated carbons from Iris tectorum employing ferric nitrate as dopant for removal of tetracycline from aqueous solutions. Ecotoxicol Environ Saf. 2013;98:273-82. doi: 10.1016/j. ecoenv.2013.08.015, PMID 24021870.

37. Balarak D, Ganji F, Chandrika K, Haseeb S. Montmorillonite nanoparticles effectiveness in removal of amoxicillin from water solutions. Int $\mathrm{J}$ Pharm Investig. 2020;10(2):122-6. doi: 10.5530/ijpi.2020.2.22.

38. Ji L, Chen W, Duan L, Zhu D. Mechanisms for strong adsorption of tetracycline to carbon nanotubes: a comparative study using activated carbon and graphite as adsorbents. Environ Sci Technol. 2009;43(7):2322-27. doi: 10.1021/ es803268b, PMID 19452881.

39. Balarak D, Chandrika K. Batch Studies on biosorption of ciprofloxacin on Freshwater Macro alga Lemna minor. Int J Pharm Investig. 2019;9(3):117-21. doi: 10.5530/ijpi.2019.3.22.

40. Ren X, Chen C, Nagatsu M, Wang X. Carbon nanotubes as adsorbents in environmental pollution management: a review. Chem Eng J. 2011;170(23):395-410. doi: 10.1016/j.cej.2010.08.045.

41. Li S, Zhang $X$, Huang $Y$. Zeolitic imidazolate framework-8 derived nanoporous carbon as an effective and recyclable adsorbent for removal of ciprofloxacin antibiotics from water. J Hazard Mater. 2017;321:711-19. doi: 10.1016/j. jhazmat.2016.09.065, PMID 27701060.

42. Wang F, Yang B, Wang H, Song $Q$, Tan F, Cao Y. Removal of ciprofloxacin from aqueous solution by a magnetic chitosan grafted graphene oxide composite. J Mol Liq. 2016;222:188-94. doi: 10.1016/j.molliq.2016.07.037.

43. Azarpira H, Mahdavi Y, Khaleghi O. Thermodynamic studies on the removal of metronidazole antibiotic by multi-walled carbon nanotubes. Pharm Lett. 2016;8(11):107-24

Article History: Submission Date : 14-09-2021; Revised Date : 10-10-2021; Acceptance Date : 13-11-2021.

Cite this article: Mostafapour FK, Bazi M, Chandrika K, Balarak D, Bagheri H. Highly Efficient Adsorption and Removal of Amoxicillin from Aqueous Solution by Magnetic Graphene Oxide Nanocomposite. Int. J. Pharm. Investigation. 2021;11(4):384-8. 